\title{
Vivência em Consultório na Rua do Rio de Janeiro: a situação de rua sob uma nova perspectiva
}

\author{
Experience in "Consultório na Rua" in Rio de Janeiro: homeless poeple from a new perspective \\ Experiencia en "Consultório na Rua" en Rio de Janeiro: las Personas sin Hogar en una nueva \\ perspectiva
}

Bruno Paladini Camargo. Centro Universitário de Araraquara/UNIARA. Araraquara, SP, Brasil. brunovest27@gmail.com (Autor correspondente)

\section{Resumo}

Objetivos: O presente relato tem como finalidade esclarecer como o Consultório na Rua utiliza-se da Redução de Danos para melhorar o cuidado à população em situação de rua, além de conscientizar profissionais da Atenção Primária à Saúde para as particularidades da população em questão. Métodos: Para tal, foi realizado estágio durante uma semana em um Consultório na Rua da cidade do Rio de Janeiro. Conclusão: Concluiu-se que a Redução de Danos é a principal estratégia para o cuidado adequado dos indivíduos em situação de rua, e que estes necessitam de uma abordagem biopsicossocial devido à sua complexidade e particularidades.

\section{Abstract}

Objectives: This report aims to clarify how the "Consultório na Rua" uses Harm Reduction to improve care to Homeless People, and educate Primary Health Care professionals to the particularities of the population in question. Methods: To do this, an internship was held for a week in a "Consultorio na Rua" at Rio de Janeiro, Brazil. Conclusion: It was concluded that Harm Reduction is the main strategy for the proper care of Homeless People, and this population needs a biopsychosocial approach because of its complexity and peculiarities.

\section{Resumen}

Objetivos: Este informe pretende aclarar cómo "Consultório na Rua" utiliza la Reducción del Daño para mejorar la atención a Personas sin Hogar, y educar a los profesionales de la Atención Primaria de Salud a las particularidades de la población en cuestión. Métodos: Para ello, se llevó a cabo prácticas de una semana en uno "Consultorio na Rua" en la ciudad de Rio de Janeiro. Conclusión: Se concluyó que la Reducción del Daño es la principal estrategia para la atención adecuada de las Personas sin Hogar, y que necesitan un enfoque biopsicosocial, debido a su complejidad y peculiaridades.

\section{Palavras-chave:}

Pessoas em Situação de Rua Redução de Danos

Atenção Primária à Saúde

\section{Keywords:} Homeless People Harm Reduction Primary Health Care

Palabras clave: Personas sin Hogar Reducción del Daño Atención Primaria de Salud
Como citar: Camargo BP. Vivência em Consultório na Rua do Rio de Janeiro: a situação de rua sob uma nova perspectiva. Rev Bras Med Fam Comunidade. 2016;11(38):1-3. http://dx.doi.org/10.5712/rbmfc11(38)1269
Fonte de financiamento: declara não haver.

Parecer CEP:

não se aplica.

Conflito de interesses:

declara não haver.

Procedência e revisão por pares: revisado por pares.

Recebido em: 29/01/2016.

Aprovado em: 09/03/2016. 
Pedaços de lona, papelão, por vezes um colchão rasgado, fios desencapados e ligações elétricas clandestinas, fogões improvisados, animais em meio a panelas de comida, crianças "brincando de ser bandido" (mas ainda com um olhar inocente, que brilha ao ver uma luva de procedimentos pela simples possibilidade de preenchê-la com água), usuários de drogas por toda a parte. Usuários de drogas? Eles se reduzem a isso? O nome, história, sofrimento, problemas de saúde, necessidade de cuidados e os direitos serão esquecidos até quando? É neste cenário que se insere o Consultório na Rua, projeto idealizado na Bahia e criado em 1999. ${ }^{1}$

Durante uma semana, foi realizado estágio observacional no Consultório na Rua da Coordenadoria de Saúde da Área de Planejamento (CAP) 3.2, no bairro do Jacarezinho - Rio de Janeiro -, movido pelo desejo de conhecer de modo profundo a realidade em que vivem, associado à curiosidade de saber qual a melhor estratégia de abordagem médica a indivíduos em situação de rua.

A realidade observada foi um verdadeiro choque de realidade, porém ao mesmo tempo trouxe à tona um senso de humanidade até então desconhecido. A situação de rua é muito mais complexa do que se pode imaginar antes de estar frente a frente com a realidade, e muitas vezes não é possível resolver todos os problemas e atender todas as demandas dessa população. Eles precisam ser cuidados do ponto de vista biológico, mas também precisam de documentação, de moradia, de emprego, de alimentação, de alfabetização, de família, de amigos, de atenção, precisam ser aceitos e enxergados além do uso de drogas. Em meio a toda essa complexidade, é que se insere a política de Redução de Danos, que é parte integrante dos programas de saúde no Brasil desde 1993; e também a Medicina Centrada na Pessoa.

A Redução de Danos busca minimizar os riscos decorrentes do uso de drogas lícitas ou ilícitas, envolvendo tanto aspectos biológicos quanto sociais e econômicos, sem que necessariamente o uso de entorpecentes esteja ausente. Sinergicamente, a Medicina Centrada na Pessoa constitui-se numa ferramenta importantíssima, que permite uma visão mais ampla e completa dos indivíduos, possibilitando uma abordagem integral e realmente efetiva dos problemas biopsicossociais. No Consultório na Rua, estas duas estratégias, adaptadas às particularidades dos usuários, se confluem necessariamente e, quando isso não é possível, o cuidado fica notoriamente prejudicado e raramente será eficaz. Como parte integrante do cuidado integral e individualizado necessário, também notou-se a diferença entre o uso da Classificação Internacional de Doenças (CID-10), que se utiliza mais de abstrações e situações objetivas, e da Classificação Internacional da Atenção Primária (CIAP), que leva em consideração também as experiências de saúde e fatores além dos biológicos.

Como se a complexidade intrínseca não se fizesse suficiente, o preconceito enraizado na sociedade como um todo está também muito presente nas estruturas da rede de atenção à saúde. No pequeno período de estágio foi possível observar em diversos momentos a negligência diária à saúde dos indivíduos, com atendimentos negados em Unidades de Saúde da Família/Clínicas da Família, mesmo que os indivíduos já possuam endereço físico/estejam vivendo em abrigos ou casas de recuperação (o que transfere a responsabilidade do cuidado às unidades que abrangem o território desses locais), consolidando ainda mais a exclusão social. Essa dificuldade de acesso ao SUS fica ainda mais explícita quando percebe-se que diversos pedidos de exames, encaminhamentos e o próprio registro dos atendimentos em prontuário eletrônico exigem o endereço do indivíduo e/ou documentação. 
Destoante de todo essa situação hostil e marginalizada, os indivíduos, a todo momento, foram sinceros, respeitosos, amigáveis, e acima de tudo agradecidos por cada mínimo cuidado, por cada mínima intervenção ou orientação. Uma experiência de humanidade e reflexão sem igual.

Ver a política de Redução de Danos sendo aplicada de forma tão completa e presenciar, nesse pequeno período de tempo, os resultados dessa abordagem; aprender com cada um dos indivíduos que se sentou à minha frente; e ver as adaptações da Medicina Centrada na Pessoa em uma situação tão peculiar e com muitas particularidades, foram apenas algumas das situações que me permitiram chegar a determinadas conclusões.

A primeira delas foi a importância inquestionável da interdisciplinaridade no cuidado dos indivíduos, uma vez que os mesmos possuem questões muito além das biológicas, e muitas vezes mais importantes, a serem resolvidas, seja a falta de documentação, a falta de moradia, o uso abusivo de drogas, o analfabetismo ou desemprego, de modo que a integração e a horizontalidade entre Médico de Família e Comunidade (MFC), equipe de enfermagem, agentes sociais, assistente social, terapeuta ocupacional e auxiliar administrativo se faz necessária a todo momento, tendo cada membro da equipe funções fundamentais para o cuidado adequado dos usuários.

A segunda conclusão diz respeito à política de Redução de Danos, que sem dúvidas é a abordagem mais adequada para esses indivíduos, uma vez que não gera confrontos, ao mesmo passo em que gera confiança e sensação de segurança dos indivíduos, promovendo saúde por meio de uma melhor relação médico-pessoa, sem represálias e julgamentos. Com essa abordagem, o tempo deles é respeitado, tornando, a longo prazo, o cuidado mais efetivo.

Essa experiência também permitiu concluir que, mesmo nos dias de hoje, em que as informações estão mais acessíveis do que nunca, o preconceito ainda se faz muito presente, estando apenas encoberto pelo "politicamente correto", sendo facilmente identificado quando tenta-se uma abordagem dos indivíduos em situação de rua que envolvam a reinserção na sociedade, seja em situações corriqueiras como entrar em uma loja de roupas ou salão de beleza, seja na busca por emprego.

O Consultório na Rua é muito mais do que se pode imaginar. Nele é possível enxergar a Medicina de Família e Comunidade sendo aplicada em sua forma mais pura, levando ao pé da letra cada página do Tratado de MFC e da Medicina Centrada na Pessoa, promovendo, prevenindo, diagnosticando, tratando de maneira integral, com equidade, sem distinções.

Por fim, a principal conclusão é que reduzir os cidadãos em situação de rua ao uso de drogas é inadmissível. Cada um desses indivíduos possui uma história, possui patologias, possui relacionamentos (ou a falta deles), e com um pouco de conversa percebe-se: possui esperança! Esperança de uma vida melhor, mais digna, sem preconceitos, de serem cuidados, de se sentirem gente novamente e serem encarados como tal por toda e qualquer pessoa, cabendo a cada um dos profissionais de saúde não permitir que essa esperança acabe.

\section{Referências}

1. Londero MFP, Ceccim RB, Bilibio LFS. Consultório de/na rua: desafio para um cuidado em verso na saúde. Interface (Botucatu). 2014;18(49):251-60. DOI: http://dx.doi.org/10.1590/1807-57622013.0738 